\title{
Ecological Adaptations in Douglas-Fir (Pseudotsuga menziesii var. glauca): a Synthesis
}

\author{
G.E. REHFELDT ${ }^{1}$ \\ USDA Forest Service, Intermountain Research Station, Ogden, Utah 84401 (U.S.A.)
}

(Accepted 2 August 1988)

\section{ABSTRACT}

Rehfeldt, G.E., 1989. Ecological adaptations in Douglas-fir (Pseudotsuga menziesii var. glauca): a synthesis. For. Ecol. Manage., 28: 203-215.

\begin{abstract}
Measurements of 3rd-year height of 228 seedling populations, grown in four separate studies in two of the same common gardens, were used to summarize patterns of genetic variation for Douglas-fir across $250000 \mathrm{~km}^{2}$ of forested lands in Idaho and Montana, U.S.A. Because each study was conducted in different years with a different set of populations, measurements were transformed to standard deviates and then were scaled according to the performance of populations common between studies. Genetic variation in 3rd-year height was related to the elevation and geographic location of the seed source by a regression model that accounted for $87 \%$ of the variance among populations. In addition, 3rd-year height of 169 of the populations was strongly correlated $(r=0.80)$ to freezing injury observed in previous studies. Both variables showed that populations from elevationally or geographically mild sites were tall but had low freezing tolerance. Populations from harsh sites were short and cold-hardy.

In Douglas-fir, adaptation to heterogeneous environments can be viewed as physiological specialization for a relatively small portion of the environmental gradient; populations separated by a relatively short distance along the environmental gradient (e.g., 20 frost-free days) tend to be different genetically.
\end{abstract}

\section{INTRODUCTION}

In some species, population differentiation occurs across environmental gradients as small as a few $\mathrm{m}$, but in others populations separated by large geographic distances are only weakly differentiated (Bradshaw, 1984). The latter category is commonly assumed to typify coniferous forest trees, largely because conifers are long-lived and wind-pollinated. However, microevolution in the conifers of western North America has followed divergent paths. Pinus monticola, for example, has an ecological distribution that encompasses over 1000

${ }^{1}$ Address for correspondence: 1221 S. Main, Moscow, Idaho 83843, U.S.A. 
$m$ of elevation (Daubenmire and Daubenmire, 1968), but genetic differentiation is difficult to detect, and clines cannot be demonstrated (Rehfeldt et al., 1984). By contrast, genetic variation in Douglas-fir (Pseudotsuga menziesii) is typically Turessonian (sensu Heslop-Harrison, 1964). When compared in common environments, natural populations of either the coastal variety $(P$. menziesii var. menziesii) or the Rocky Mountain variety ( $P$. menziesii var. glauca) differ in morphological and physiological characters, and much of the genetic variation can be correlated with environmental differences at the seed source (Campbell and Sorensen, 1978; Rehfeldt, 1978; Campbell, 1986).

The relatively steep clines that describe genetic variation in $P$. menziesii var. glauca, the subject of this paper, are associated with steep environmental gradients. In Idaho and Montana, a climatic gradient from west to east occurs across a series of rugged mountain ranges. To the northwest (Fig. 1), Douglasfir occurs at relatively low elevations where frost-free periods are generally long and the climate can be mild and moist (Daubenmire and Daubenmire, 1968). To the east and southeast, the elevation of valley floors increases, the frost-free period decreases, and the climate becomes arid. East of the Continental Divide, winters are severely cold and the scant precipitation occurs primarily in brief summer storms (Anonymous, 1968). These climatic gradients allow the region to be considered as four physiographic provinces which differ climatically, floristically and ecologically, and between which the Salmon River, the Bitterroot Range and the Continental Divide (Fig. 1) form rough boundaries. Within each province, moreover, Douglas-fir faces not only frost-free periods that decrease by about 80 days across an elevational interval of 1000 m (Baker, 1944), but also the heterogeneous edaphic and microclimatic conditions that typify the mountainous terrain (Daubenmire and Daubenmire, 1968).

In response to this environmental heterogeneity, natural populations of Douglas-fir are genetically differentiated for numerous traits, and differentiation is closely related to the elevation and geographic location of the seed source (Rehfeldt, 1979, 1982, 1983a, 1988). Genetic variation is indirectly correlated with the length of the growing season, a period that is terminated by frost but commonly interrupted by drought. When grown in common gardens, seedlings adapted to long growing seasons initiate shoot elongation twice before midsummer, cease elongation late, are tall, but are susceptible to injury from early fall frosts. Seedlings from regions where growing seasons are short tend to initiate shoot elongation only once each growing season, are small, but are also frost-hardy. Coherence (Clausen and Hiesey, 1960) thus describes adaptive differentiation: suites of intercorrelated traits have been molded to growing seasons of variable length.

The previous papers of this series (Rehfeldt, 1979, 1982, 1983a, 1988) dealt with genetic variation within each of the four physiographic provinces that comprise the region of study: northern Idaho and northeastern Washington (NI), nor'hwestern Montana (NWM), central Idaho (CI), and southwestern 


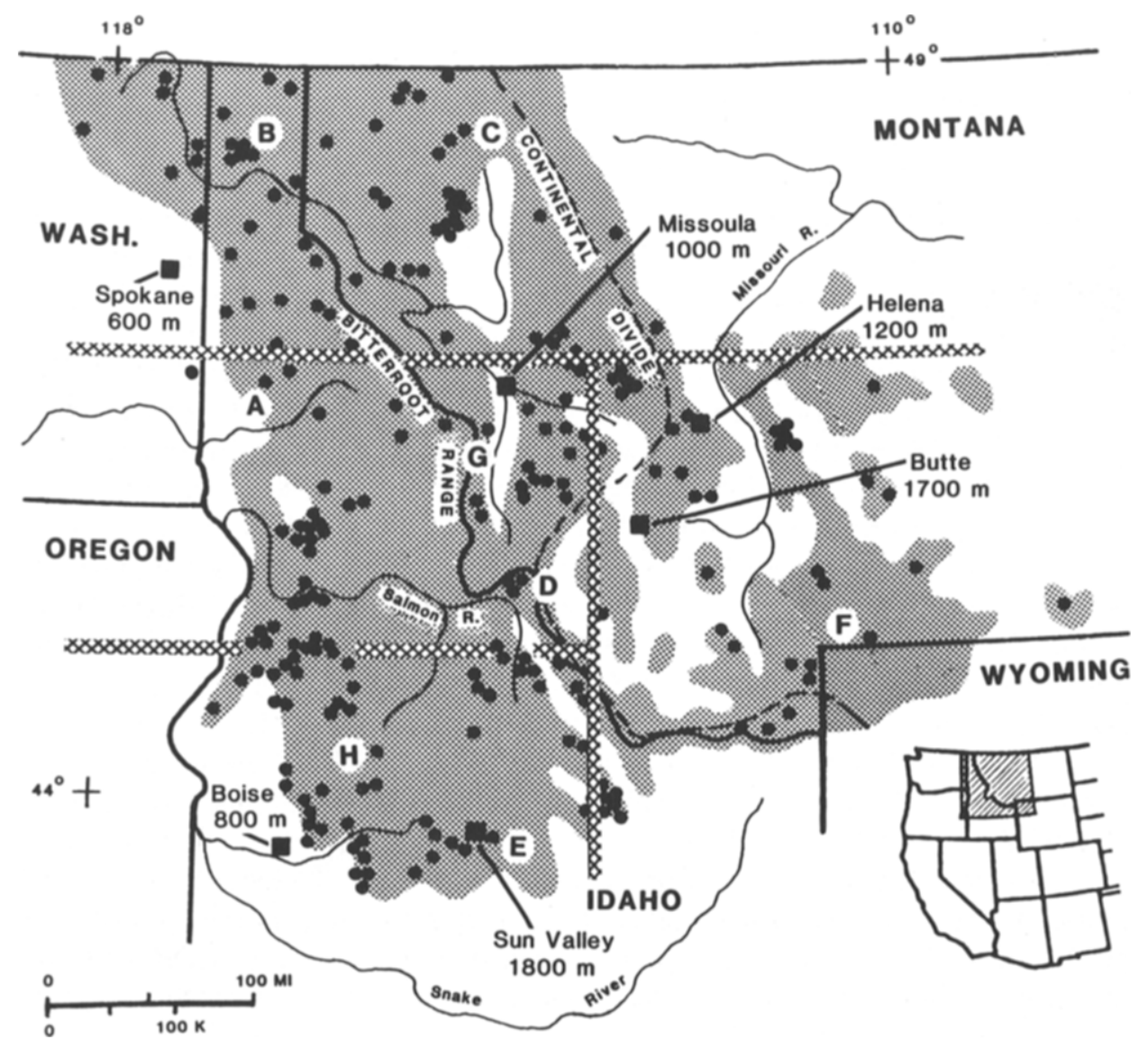

Fig. 1. Geographic distribution (shading; Little, 1971) and populations sampled in the region of study. The Bitterroot Range, Salmon River and Continental Divide demark the regions into four physiographic provinces. Cross-hatching outlines the grouping of populations for regression analyses. Letters key the elevational clines of Fig. 2.

Montana and adjacent Idaho (SWM). This paper synthesizes common garden studies of 228 populations and develops a model of genetic variation that describes microevolution within a heterogeneous region of approximately 250000 $\mathrm{km}^{2}$ of forested lands.

\section{PROCEDURES}

Each of the four studies of this series followed experimental procedures similar to those of Clausen et al. (1940): wind-pollinated cones were collected from natural populations; seedlings were grown for 3 years in randomized complete blocks in at least two of the same common gardens (at $900-\mathrm{m}$ and $1500-\mathrm{m}$ 
elevation near Priest River in northern Idaho); and seedling populations were compared according to several (6-8) traits reflecting growth, development, and frost tolerance. In all studies, adaptive differences were reflected in a suite of intercorrelated traits. Correlations were so strong $(r>0.75)$ for traits such as date of bud set, height, and injury from fall, winter or spring freezing that the entire suite can be indexed by single traits. In this paper, 3rd-year height is used to index adaptive differentiation. Although this variable was the only trait common to all studies, it also was the most strongly correlated with the other traits, it provided greatest resolution of population differentiation, and it was relatively free of genotype and environment interactions except those attributable merely to the scale of measurement.

Altogether, the four studies sampled 228 populations (Fig. 1), some of which were included in more than one study (Table 1) and thus provide a link between studies. Because of heterogeneous means and variances, linking the studies required that the separate data sets be transformed and scaled to obtain a single dataset within which the performance of a population tested in one study was directly comparable with the performance of populations tested in other studies.

To eliminate the effects of different testing years, data within each study were transformed to standard normal deviates for each test site:

$Z_{i j k l}=\left(X_{i j k l}-\bar{x}_{j k}\right) / \sigma_{j k}$

where $Z_{i j k l}$ is a standard deviate for seedling $l$ from population $i$ tested in study $j$ on site $k ; X$ is an original observation; and $\bar{x}_{j k}$ and $\sigma_{j k}$ are the mean and standard deviation of all individuals at site $k$ of study $j$.

Next, standardized population means for each study $\left(\bar{Z}_{i j}\right)$, based on 48-60 individuals, were scaled to those from physiographic province SWM according

\section{TABLE 1}

Number of populations from each geographic province composing each study

\begin{tabular}{lcccc}
\hline \multirow{2}{*}{ Province of study } & \multicolumn{5}{c}{ Geographic origin of populations } \\
\cline { 2 - 5 } & NI & NWM & CI & SWM \\
\hline NI & 48 & & 1 & \\
NWM & $5^{\mathbf{a}}$ & 50 & 3 & 1 \\
CI & 5 & & 69 & \\
SWM & 1 & $6^{\text {b }}$ & $9^{\text {c }}$ & 61
\end{tabular}

$\mathrm{NI}=$ Northern Idaho and Northeast Washington; NWM = Northwestern Montana; $\mathrm{CI}=\mathrm{Central}$ Idaho; SWM = Southwestern Montana adjacent to Idaho.

aThree of which were used to calculate scaling factor 1 .

bUsed to calculate scaling factor 2.

'Used to calculate scaling factor 3 . 
to the differential performance of populations common to the various studies. Thus, a mean standard deviation $\left(\bar{Z}_{i}^{\prime}\right)$ was defined such that:

if $j=\mathrm{SWM}=4$, then $\bar{Z}_{i}^{\prime}=\bar{Z}_{i 4}$

if $j=\mathrm{CI}=3$, then $\bar{Z}_{i}^{\prime}=\bar{Z}_{i 3}+\mathrm{SF} 3$

if $j=\mathrm{NWM}=2$, then $\bar{Z}_{i}^{\prime}=\bar{Z}_{i 2}+\mathrm{SF} 2$

if $j=\mathrm{NI}=1$, then $\bar{Z}_{i}^{\prime}=\bar{Z}_{i 1}+\mathrm{SF} 1+\mathrm{SF} 2$

where: SF3, scaling factor $3=0.5364$, the average difference between the SWM and CI performance of seedlings from nine populations common to both tests; and $\mathrm{SF} 2=0.8856$, the average difference between the SWM and NWM performance of seedlings from six populations common to both tests; and $\mathrm{SF} 1=2.0863$, the average difference between the NI and SWM performance of seedlings from three populations common to both tests.

These procedures left seven populations that had been tested in more than one study but had not been used to calculate scaling factors. The mean height of seedlings from these populations could be scaled to SWM according to alternative scaling routes and could, therefore, be used to judge the effectiveness of the scaling procedure. For the 11 possible comparisons (Table 2), the average difference $(0.3243)$ in values derived from alternative scalings is less than the standard error of the mean $\left(s_{\bar{x}}=0.3714\right)$. In fact, for only two of the comparisons, both of which involve population 101 in study NI, were the differences greater than $s_{\bar{x}}$. This indicates that residual biases not removed by scaling generally lie within the tolerances associated with the errors of sampling and experimentation.

Scaled values were used as a dependent variable in multiple-regression analyses, the objective of which was to describe elevational and geographic patterns of genetic variation rather than to test causal effects of individual environmental factors. This objective was adopted because weather stations in the mountains of the western U.S. are not only few, but also tend to be located on valley floors. Environmental gradients such as those published by the U.S. Department of Commerce (Anonymous, 1966) illustrate general patterns but are greatly extrapolated and incapable of accurately describing environmental conditions at specific locations. As a result, environmental factors such as the average length of the frost-free period, which appear to be operative in natural selection, cannot be determined for individual sites.

Describing patterns of variation, therefore, required independent variables to serve as aliases for the complex 3-dimensional patterns that characterize operative environmental gradients. Geographic variables were derived from the four coordinates: latitude (LT), longitude (LN), northwest departure (NW), and southwest departure (sw). The last two were defined as the products of LT with $\mathrm{LN}$ and $\mathrm{LN}$ with $\mathrm{LT}^{-1}$, respectively, and were included to accommodate 
TABLE 2

Scaling routes and scaled values for seven populations ( $i$ ) common between studies $(j)$ but not used to calculate scaling factors (SF)

\begin{tabular}{|c|c|c|}
\hline Population ( $i$ ) & Scaling route & Scaled value $\left(\bar{Z}_{i}^{\prime}\right)$ \\
\hline 101 & $\begin{array}{l}\bar{Z}^{\prime}{ }_{i 1}+\mathrm{SF} 1+\mathrm{SF} 2 \\
\bar{Z}^{\prime}{ }^{3}+\mathrm{SF} 3 \\
\bar{Z}^{\prime}{ }_{\mathrm{i} 4}+{ }^{2}\end{array}$ & $\begin{array}{l}2.5895 \\
3.2872 \\
3.0490\end{array}$ \\
\hline 106 & $\begin{array}{l}\bar{Z}^{\prime}{ }_{i 1}+\mathrm{SF} 1+\mathrm{SF} 2 \\
\bar{Z}^{\prime}{ }^{\prime}+\mathrm{SF} 3 \\
\bar{Z}^{\prime}{ }_{\mathrm{i} 4}+{ }_{4}\end{array}$ & $\begin{array}{l}2.7133 \\
2.7665 \\
3.0496\end{array}$ \\
\hline 302 & $\begin{array}{l}\bar{Z}^{\prime}{ }_{11}+\mathrm{SF} 1+\mathrm{SF} 2 \\
\bar{Z}^{\prime}{ }_{\mathrm{i} 3}+\mathrm{SF} 3\end{array}$ & $\begin{array}{l}1.6168 \\
1.2705\end{array}$ \\
\hline 311 & $\begin{array}{l}\bar{Z}_{{ }^{2} 2}+\text { SF2 } \\
\bar{Z}^{\prime}{ }^{4} 4\end{array}$ & $\begin{array}{l}-0.5431 \\
-0.8002\end{array}$ \\
\hline 314 & $\begin{array}{l}\bar{Z}^{\prime}{ }^{2}+\mathrm{SF} 2 \\
\bar{Z}^{\prime}{ }^{2}{ }^{4} 4\end{array}$ & $\begin{array}{l}-0.6584 \\
-0.3424\end{array}$ \\
\hline 315 & $\begin{array}{l}\bar{Z}_{{ }_{\mathrm{i} 2}}^{\prime}+\mathrm{SF} 2 \\
\bar{Z}_{\mathrm{i} 3}+\mathrm{SF} 3\end{array}$ & $\begin{array}{l}-0.3267 \\
-0.5502\end{array}$ \\
\hline 401 & $\begin{array}{l}\bar{Z}^{\prime}{ }^{\prime}{ }_{2}+\mathrm{SF} 2 \\
\bar{Z}^{\prime}{ }^{2}{ }^{2}\end{array}$ & $\begin{array}{l}-1.7449 \\
-1.3886\end{array}$ \\
\hline
\end{tabular}

Effectiveness of scaling can be judged by comparing differences between scaled values for a given population against the standard error of the mean $\left(s_{\bar{x}}=0.3714\right)$, which was pooled from the four original studies.

geographic patterns that might be oblique to LT or LN. The four geographic variables plus their squares and cubes also were nested within the four geographic subdivisions outlined by the cross-hatching in Fig. 1. Nested variables were defined such that LT in subdivision 1 (LT1), for instance, equalled LT if population $i$ was in subdivision 1 ; otherwise $L T 1=0$. The boundaries of the subdivisions were selected so that: (1) populations were relatively equally distributed; (2) boundaries passed through areas intensively sampled; (3) boundaries did not conform to the physiographic provinces of the original studies; and (4) boundaries did not coincide with obvious physiographic features or environmental gradients. These measures assured that the procedure by which independent variables were nested within geographic subunits would not bias the results.

Independent variables also included 1st and 2nd powers of elevation which provided for the possibilities of either linear or nonlinear elevational clines. However, because elevation and geography are not independent in this region, nonlinearity would also allow the slope of the elevational cline to vary geographically.

These procedures produced 62 independent variables that were screened by 
stepwise regression models for maximizing $R^{2}$ (Anonymous, 1982). The independent variables, however, were developed from only three variables and, therefore, multicolinearity was pronounced. Consequently, only a portion of the variables could be screened by a particular model without producing a variance/covariance matrix that was singular when inverted. Of the numerous combinations possible, the group of 26 independent variables presented in Table 3 produced a variance/covariance matrix that could be inverted without singularity and provided results that were as sound statistically as those of any model tested. The best model was defined as that for which: (1) the probability

TABLE 3

Independent variables used for stepwise analyses, regression coefficients and tests of significance

\begin{tabular}{|c|c|c|}
\hline Independent variable & Regression coefficient & $F$-Value \\
\hline Intercept & 1130.4259 & \\
\hline EL & $-3.5311 \times 10^{-3}$ & 32.42 \\
\hline$(\mathrm{EL})^{2}$ & $6.8456 \times 10^{-7}$ & 12.72 \\
\hline LT & -59.4036 & 43.64 \\
\hline LT1 & -3.2033 & 54.85 \\
\hline LT2 & -3.9808 & $68.22^{* *}$ \\
\hline LT3 & 5.3975 & $44.36^{* *}$ \\
\hline \multicolumn{3}{|l|}{ LN } \\
\hline LN1 & 1.3239 & 54.53 \\
\hline I.N2 & 51.4983 & 37.62 \\
\hline \multicolumn{3}{|l|}{ LN3 } \\
\hline $\mathrm{NW}$ & 0.3649 & 38.07 \\
\hline \multicolumn{3}{|l|}{ NW1 } \\
\hline NW2 & -0.5280 & 33.86 \\
\hline \multicolumn{3}{|l|}{ NW3 } \\
\hline \multicolumn{3}{|l|}{ sw } \\
\hline \multicolumn{3}{|l|}{ sw1 1} \\
\hline sw2 & -1177.0781 & $37.44^{* *}$ \\
\hline sw3 & -266.9358 & $46.50^{* *}$ \\
\hline$(\mathrm{LT})^{3}$ & $3.7102 \times 10^{-3}$ & $20.00^{* *}$ \\
\hline$(\mathrm{LN})^{3.3}$ & $4.0296 \times 10^{-4}$ & $39.90^{* *}$ \\
\hline$(\mathrm{NW})^{3}$ & $5.0188 \times 10^{-10}$ & $8.39^{* *}$ \\
\hline \multicolumn{3}{|l|}{$(\mathrm{sw})^{: 3}$} \\
\hline \multicolumn{3}{|l|}{$(\mathrm{sw} 1)^{2}$} \\
\hline \multicolumn{3}{|l|}{$(\mathrm{sw} 2)^{2}$} \\
\hline$(\mathrm{sw} 3)^{2}$ & 67.7424 & 47.25 \\
\hline$(\mathrm{sw} 4)^{2}$ & & \\
\hline
\end{tabular}

$\mathrm{EL}=$ elevation, $\mathrm{LT}=$ latitude, $\mathrm{LN}=$ longitude, $\mathrm{SW}=$ southwest departure, $\mathrm{NW}=$ northwest departure. Numerals 1 to 4 code the northern, west-central, southwestern and eastern geographic zones, respectively, outlined in Fig. 1. Geographic variables are in degrees, and elevation is in $\mathrm{m}$.

* Statistical significance at the $5 \%$ level.

**Statistical significance at the $1 \%$ level. 
of statistical significance was at least $0.99 ;(2)$ the Mallows statistic first equalled the number of included variables; and (3) no elevational or geographical patterns were displayed by the residuals (Draper and Smith, 1981). By using the Mallows statistic, assurance is provided that a particular model is the least biased of all other models capable of being developed from a particular group of independent variables.

\section{RESULTS}

The best-fitting regression model (Table 3 ) included 16 independent variables and accounted for $87 \%$ of the variance among populations for standardized 3-year height, $\bar{Z}^{\prime}$ ( $R^{2}$ adjusted for the degrees of freedom was 0.86 ). The model describes genetic variation as occurring along elevational (Fig. 2) and geographic (Fig. 3) clines. Differentiation along both clines is evaluated according to the least significant difference among populations (Steel and Torrie, 1960 ) at the 0.05 level of probability - $\mathrm{LSD}_{0.05}$. Values of LSD, calculated from an analysis of variance, are quantified in Fig. 2 and represent the intervals between isopleths in Fig. 3. Thus, populations are expected to differ with a probability of about 0.95 if they are separated either by (1) a distance equaling the geographic interval between isopleths (Fig. 3), or by (2) an elevational interval that subtends a mean difference equal to LSD (Fig. 2 ).

The manner by which the model describes genetic variation is illustrated in Fig. 2, which presents the elevational clines predicted for eight geographic localities, two from each of the region's four physiographic provinces. Differen-

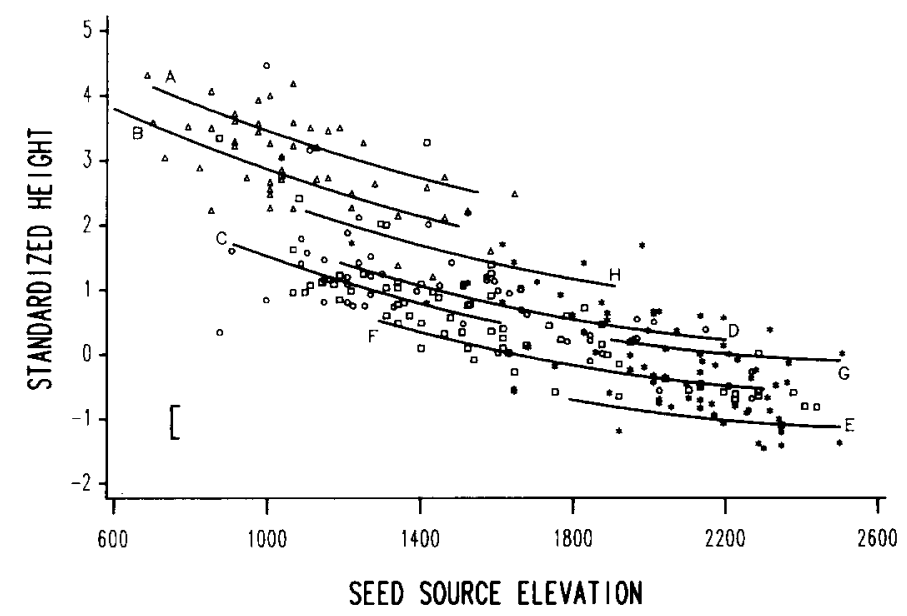

Fig. 2. Elevational clines for eight localities (A-H) keyed to Fig. 1. Brackets quantify the least significant difference among populations at the $95 \%$ level of probability. Length of the regression lines reflects the elevational distribution of Douglas-fir at each locality. $\Delta=\mathrm{NI}, \square=\mathrm{CI}, \mathrm{O}=\mathrm{WM}$, $*$ SWM. 


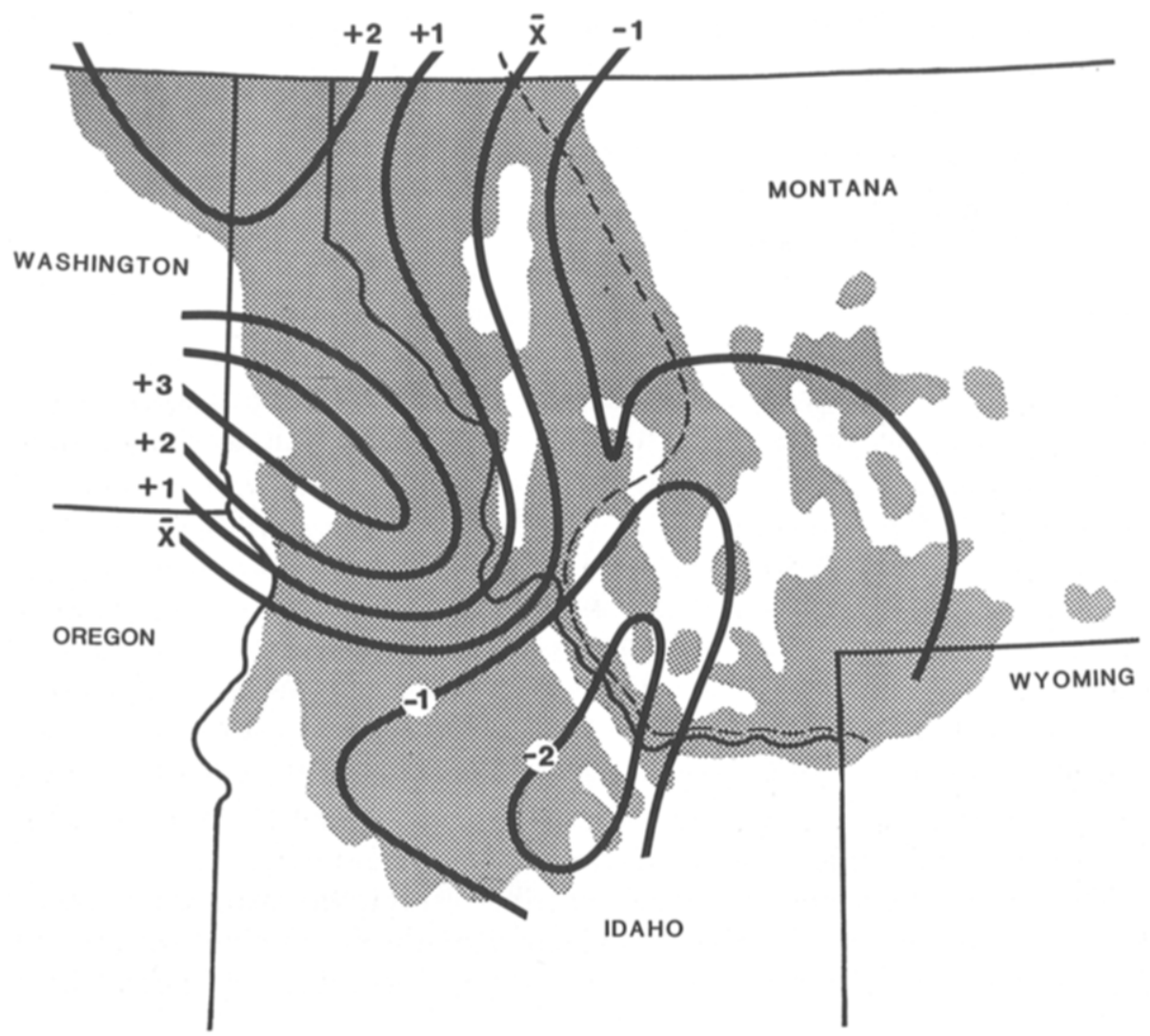

Fig. 3. Geographic patterns of variation predicted for $1500-\mathrm{m}$ elevation and presented as isopleths of equal performance. The contour interval equals the least significant difference among populations at the $95 \%$ level of probability. Shading represents the distribution of the species.

tiation associated with specific geographic localities is illustrated by regression lines of different intercept; that associated with elevation occurs along the slope of a regression line. Differentiation thus is represented by a series of regression lines with precisely the same shape but with much different geographic intercepts.

The elevational cline (Fig. 2) shows that the mean height of seedling decreased as the elevation of the seed source increased. However, the cline is definitely nonlinear; rates of genetic change are much greater at low elevations than at high. At elevations below $1000 \mathrm{~m}$, populations separated by $240 \mathrm{~m}$ will be genetically different at the $95 \%$ level of probability, but near $1500 \mathrm{~m}$ populations must be separated by $350 \mathrm{~m}$ for differentiation to be likely at the same level of probability. Above $2000 \mathrm{~m}$, differentiation fails to exceed $\mathrm{LSD}_{0.05}$. Because the frost-free period declines by 80 days across an elevational interval of 
$1000 \mathrm{~m}$ (Baker, 1944), genetic differentiation at low elevations is associated with an environmental difference of about 20 frost-free days. But at high elevations, either appropriate genetic variability has been exhausted or the environment has been perceived as homogeneously severe.

The geographic component of genetic variation is illustrated in detail in Fig. 3 where values predicted for a constant elevation, $1500 \mathrm{~m}$, are presented as isopleths. This figure shows that, among populations from the same elevation, those from northern Idaho were the tallest. Mean height decreased in populations from east of the rugged Bitterroot Range and south of the Salmon River. The pattern (Fig. 3) generally outlines the region's four physiographic provinces and therefore roughly conforms to general climatic and ecologic gradients. As shown by the U.S. Department of Commerce (Anonymous, 1968), the frost-free period near locality A (Fig. 1) can average 150 days. From this area, the frost-free period on the valley floor decreases in all directions, but the gradient is particularly steep to the south and to the east. Near G and H (Fig. 1 ), for instance, the frost-free period on the valley floor averages 90 days, and near $\mathrm{E}$ and $\mathrm{F}$, the frost-free period averages only 60 days. These gradients, moreover, are accentuated by patterns of precipitation. In the south and southeast, precipitation at low elevations can average as little as $30 \mathrm{~cm}$, and drought can interrupt growth and development and thereby magnify the effects of a short frost-free period.

Because no provisions were made for estimating separate slopes for the elevational cline in various geographic localities, the model produced elevational clines of exactly the same shape for all localities. However, no evidence suggests that this constraint resulted in the misrepresentation of general patterns of genetic variation. First, it is obvious in Fig. 2 that the elevational clines adequately fit the data from each of the four physiographic provinces. Secondly, rates of differentiation along the elevational clines (Fig. 2) differ little from those estimated previously (Rehfeldt, 1979, 1982, 1983a, 1988) and separately for each province. And thirdly, the modeling constraint in fact did not prevent the slope of the elevational cline from varying geographically. Geographic interaction was accommodated with a nonlinear slope in a region where elevation and geographic regions are intercorrelated. Thus, the elevational cline (Fig. 2) is steepest in NI where Douglas-fir occurs at the lowest elevations. But in SWM, where the species occurs at only high elevations, the cline is nearly flat.

\section{DISCUSSION}

The multiple-regression analyses produced a model of genetic variation that: (1) accounted for $87 \%$ of the variance among Douglas-fir populations of Idaho and Montana; (2) described patterns of genetic variation that have ready microevolutionary interpretation; and (3) corroborated and coordinated results 
of previous studies that were done separately for the four physiographic provinces that constitute the region (but were not used as independent variables in constructing the model).

Adaptive differentiation in this region is interpretable as a primary response to selection by a variable frost-free period. As the frost-free period decreases either elevationally or geographically, the growth potential of seedling populations also decreases. Since this response is occurring in a region where the operative environment grades in two directions simultaneously, similar environments and therefore similar genotypes tend to recur at different elevations in separated localities. Populations of high growth potential (2.5 standardized units above the mean, for example) occur at $1000 \mathrm{~m}$ at locality $\mathrm{H}$, at $1300 \mathrm{~m}$ at B, and at $1400 \mathrm{~m}$ near A (Fig. 2).

Although the present analyses involved only seedling height, Fig. 4 illustrates that selection is operating on a suite of intercorrelated traits. In this figure, the freezing injury (from Rehfeldt, 1986) to 169 of the populations represented herein is strongly correlated $(r=-0.81)$ with standardized height, and both variables are closely related to the elevation of the seed source ( $r=-0.66$ for injury and -0.81 for height). This figure affirms that population adaptation can be viewed as a balance between selection for high coldhardiness in severe environments and selection for high growth potential in mild environments.

Regardless of how sensible the results may be, models are subject to the errors of sampling, errors of experimentation, and bias from the modeling procedures. Models thus require verification with independent data. In the pres-

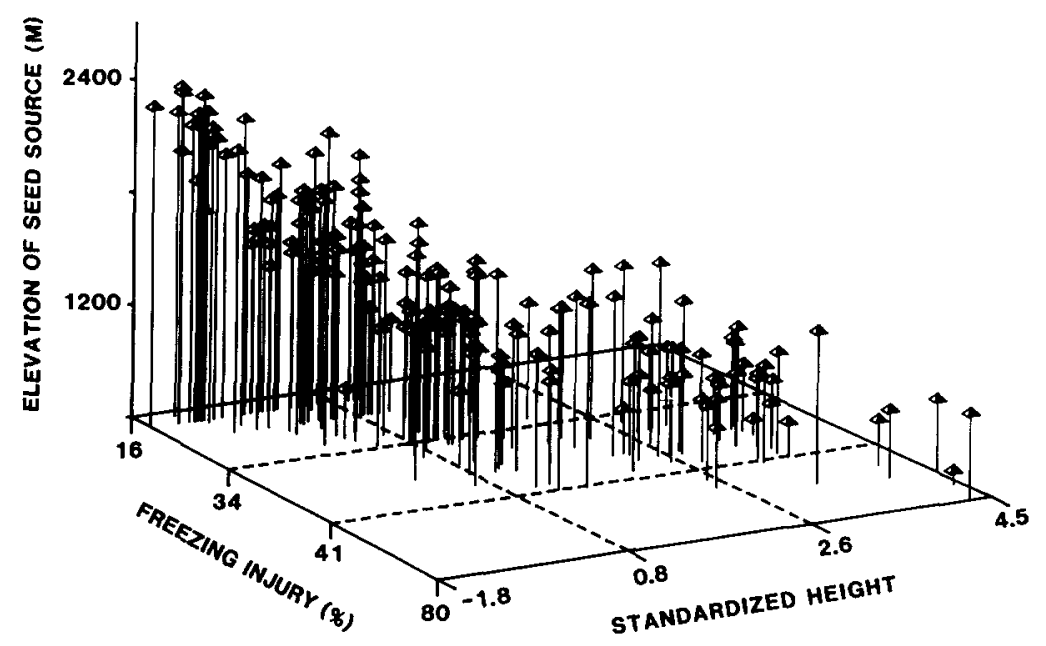

Fig. 4. Relationship between freezing injury (transformed from weighted logits to percentages) of populations (Rehfeldt, 1986), standardized height, and elevation of the seed source for 169 populations. 
ent case, Monserud and Rehfeldt (1988) correlated the genetic variability predicted by this model with the mean 50-year height of three trees in each of 135 wild populations in NI and the northwestern portion of NWM. Even though environmental effects on the phenotypic variance of these wild populations were neither controlled, uniform, nor standardized, genetic variability predicted by the model of Table 3 accounted for $42 \%$ of the variance in 50 -year height of these natural populations. This proportion was not only statistically significant ( $1 \%$ level of probability), but also was larger than the proportion accounted by variables reflecting phytosociology, soil chemistry, physiography and geography. The results not only provide strong validation of the model of genetic variation, but also underscore the importance of the genetic system in understanding basic forest biology.

Thus, microevolution in $P$. menziesii var. glauca has produced populations that are physiologically specialized for particular segments of the environmental gradient. Nevertheless, substantial genetic variability exists within populations (Rehfeldt, 1983b). Although migration, mutation, and the founder effect undoubtedly contribute to intrapopulation variability, much of this variation likely results from variable selection pressures associated with temporal environmental heterogeneity within and between generations. For longlived stationary organisms, temporal heterogeneity is repeated in space and thereby places an upper limit on the degree to which specialization can develop (Bryant, 1976).

\section{ACKNOWLEDGEMENTS}

The excellent technical assistance of S.P. Wells is gratefully acknowledged. Drs. D.T. Lester, R.K. Campbell, W.J. Libby, and D.G. Joyce provided helpful criticism on an early version.

\section{REFERENCES}

Anonymous, 1968. Climatic Atlas of the United States. U.S. Dept. Commerce, Environmental Data Service, Washington, DC.

Anonymous, 1982. SAS Users' Guide: Statistics (Version 5 edition). SAS Institute, Cary, NC, $596 \mathrm{pp}$.

Baker, F.S., 1944. Mountain climates of the western United States. Ecol. Monogr., 14: 223-254.

Bradshaw, A.D., 1984. Ecological significance of genetic variation between populations. In: R. Drizo and J. Sarukhan (Editors), Perspectives on Plant Population Ecology. Sinauer Associates Inc., Sunderland, Mass., pp. 213-228.

Bryant, E.H., 1976. A comment on the role of environmental variation maintaining polymorphisms in natural populations, Evolution, 30: 188-190.

Campbell, R.K., 1986. Mapped genetic variation of Douglas-fir to guide seed transfer in southwest Oregon. Silvae Genet., 35: 85-96.

Campbell, R.K. and Sorensen, F.C., 1978. Effects of test environment on expression of clines and on delimitation of seed zones in Douglas-fir. Theor. Appl. Genet., 51: 233-246. 
Clausen, J. and Hiesey, W.M., 1960. The balance between coherence and variation in evolution. Proc. Nat. Acad. Sci. U.S.A., 46: 494-506.

Clausen, J., Keck, D.D. and Hiesey, W.M., 1940. Experimental studies on the nature of species. I. The effect of varied environments on western American plants. Carnegie Inst. Washington, Publ. 520.

Daubenmire, R. and Daubenmire, J.B., 1968. Forest vegetation of eastern Washington and northern Idaho. Washington Agricultural Exp. Stn., Pullman, Tech. Bull. 60.

Draper, N.R. and Smith, H., 1981. Applied Regression Analysis. John Wiley, New York, 407 pp.

Heslop-Harrison, J., 1964. Forty years of genecology. Adv. Ecol. Res., 2: 159-247.

Little, E.J., Jr., 1971. Atlas of United States Trees. Vol. 1. Conifers and Important Hardwoods. USDA Misc. Publ., 1146, Washington, D.C.

Monserud, R.A. and Rehfeldt, G.E., 1988. Genetic and environmental components of variation in site index of inland Douglas-fir. For. Sci. (in press).

Rehfeldt, G.E., 1978. Genetic differentiation of Douglas-fir populations from the Northern Rocky Mountains. Ecology, 59: 1264-1270.

Rehfeldt, G.E., 1979. Ecological adaptations in Douglas-fir (Pseudotsuga menziesi var. glauca) populations. I. North Idaho and northeast Washington. Heredity, 43: 383-397.

Rehfeldt, G.E., 1982. Ecological adaptations in Douglas-fir populations. II. Western Montana. USDA For. Serv. Intermountain Res. Stn., Res. Pap. INT-295, 8 pp.

Rehfeldt, G.E., 1983a. Ecological adaptations in Douglas-fir (Pseudotsuga menziesi var. glauca) populations. III. Central Idaho. Can. J. For. Res., 13: 626-632.

Rehfeldt, G.E., 1983b. Genetic variability within Douglas-fir populations: Implications for tree improvement. Silvae Genet., 32: 9-14.

Rehfeldt, G.E., 1986. Development and verification of models of freezing tolerance for Douglasfir populations in the Inland Northwest. USDA For. Serv. Intermountain Res. Stn., Res. Pap. INT-369, 5 pp.

Rehfeldt, G.E., 1988. Ecological adaptations in Douglas-fir (Pseudotsuga menziesii var. glauca). IV. Montana and Idaho near the Continental Divide. West. J. Appl. For., 3: 101-105.

Rehfeldt, G.E., Hoff, R.J. and Steinhoff, R.J., 1984. Geographic patterns of genetic variation in Pinus monticola. Bot. Gaz., 145: 229-239.

Steel, R.G.D., and Torrie, J.H., 1960. Principles and Procedures of Statistics. McGraw-Hill, New York, $481 \mathrm{pp}$. 